\title{
Assessments of infiltration rate and effects on water quality of selected infiltration media for use in storm water run off in Karachi, Pakistan
}

\author{
A. Zubair \& M. A. Farooq \\ Department of Environmental Sciences, Federal Urdu University of Arts, \\ Science \& Technology (FUUAST), Karachi, Pakistan
}

\begin{abstract}
Infiltration experiments were undertaken to establish the suitability of soil type in terms of infiltration rates among the various soil, and to investigate the potential effects of the infiltration media on the water quality by the stormwater runoff. In all from thirty three sampling points, five different types of soil have been classified on the basis of composition of sand, silt and gravel and tested on small scale to get a preliminary estimate regarding their suitability as infiltration media. Water quality tests are conducted on stormwater to assess the effects of the medium. Soil samples from various soil types were taken prior to and after infiltration of storm water runoff. The samples were tested for trace metals $(\mathrm{Pb}$, $\mathrm{Cu}, \mathrm{Cd}$, and $\mathrm{Zn}$ ) and for major ions $(\mathrm{Ca}, \mathrm{Mg}, \mathrm{Na}$ and $\mathrm{K})$. The result shows that there is a decline in the concentration of all the metals studied during and after infiltration of stormwater runoff. It suggest that presence of sand, silt and gravel and the absence of clay particles in the effluent is responsible for declining effect of cations as the leaching of soil has not occurred. Therefore the declining effects of cations are significant in all the soil types.
\end{abstract}

Keywords: assessment, infiltration rate, infiltration media, soil types, soil characteristics, storm water, run off, trace metals, major cations, water quality.

\section{Introduction}

With the rapid development in the effective control of point source pollutants, the proportion of pollutant from run off into receiving waters is raising in recent 
years. As a result groundwater suffers from serious eutrophication in rainy seasons or after storm water events (Liu et al. [1]).

Storm water infiltration has been shown to affect groundwater quality and quantity (Ku et al. [2]; Appleyard [3]; Wilde [4]). The importance of infiltration rate in the soils cannot be ignored because if the rate of infiltration is too slow, the retention may cause property damage and threaten public safety, and if the infiltration rate is too fast, may adversely affect the ground water quality, Washington State department of Transportation [5].

Storm water runoff is rainfall or impervious surfaces like buildings, roads, etc. drains into natural or manmade drainage ways. The development of urbanization enlarges the impermeable surface area. This makes the flow of storm water runoff bigger and the pollution more serious (Wang et al. [6]).

The pollutants considered for this study are trace metals such as $\mathrm{Cd}, \mathrm{Cu}, \mathrm{Pb}$ and $\mathrm{Zn}$ which originate from material decomposition (Ferguson and Deak [7]) and major cations such as $\mathrm{Ca}, \mathrm{Mg}, \mathrm{Na}$ and $\mathrm{K}$. Each of the target pollutants is detected in all the samples collected for study. The data collected will help us in assessing the potential for degrading the quality of ground water resources associated with the infiltration of storm water runoff.

The rate of infiltration of soils is depended on soil characteristics couple with its texture and water content present in it (Ellington and Ferguson [8]). The study is also undertaken to establish the suitability of soil types in terms of infiltration rates among the various soils types.

In all, five different types of soil have been categorized on the basis of variable composition of sand, silt and gravel from the study area and are tested on a small scale to get a preliminary estimate regarding the suitability in terms of their infiltration rates. These tests are not designed to describe the hydrological properties of any soil types, and are used only as a screening tool to narrow the choice of infiltration, soil that appear to be ideal type in terms of infiltration.

\section{Sample collection and methodology}

Soil samples were carried out during the post monsoon period 2007. These samples were collected at a depth of 20 to 30 feet approximately from thirty three sampling locations (Fig. 1). This has been analyzed for particle size distribution using sieve analysis to evaluate their performance with respect to effectiveness in infiltration and removal of pollutants on the basis soil characteristics.

In addition, analysis for stormwater were carried out prior to infiltration, half way to infiltration and at the end of the experiment for the major cations and trace metals to evaluate the metal attenuation in the soil.

A constant mass of 1500 grams of the soil sample is used for the determination of infiltration rate for all soil types. Samples were dried completely at $105^{\circ} \mathrm{C}$ for 24 hour prior to the infiltration experiment. An infiltration rate is determined for both dry and wet media. 


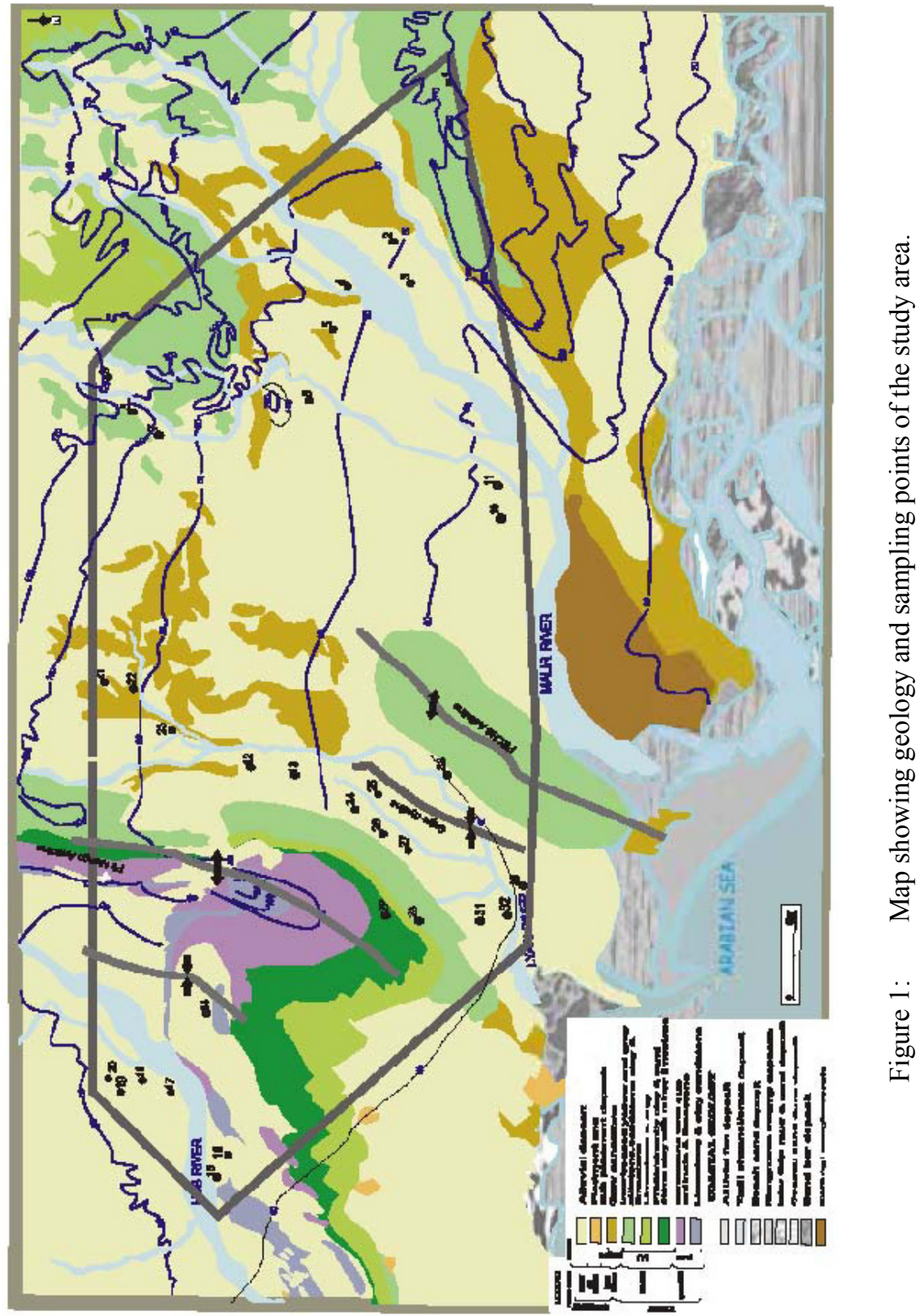


For wet media, the soil column structure is so designed and constructed with the intention of modeling one-dimensional infiltration of water through approximately $60 \mathrm{~cm}$ of soil. Since metals are to be measured, therefore the use of any metal material in the apparatus is avoided as much as possible. The column is constructed of $80 \mathrm{~mm}$ diameter PVC pipe with two sampling port placed at $30 \mathrm{~cm}$ intervals along the length of the column with an exit sampling port at the bottom of the column (Fig. 2).

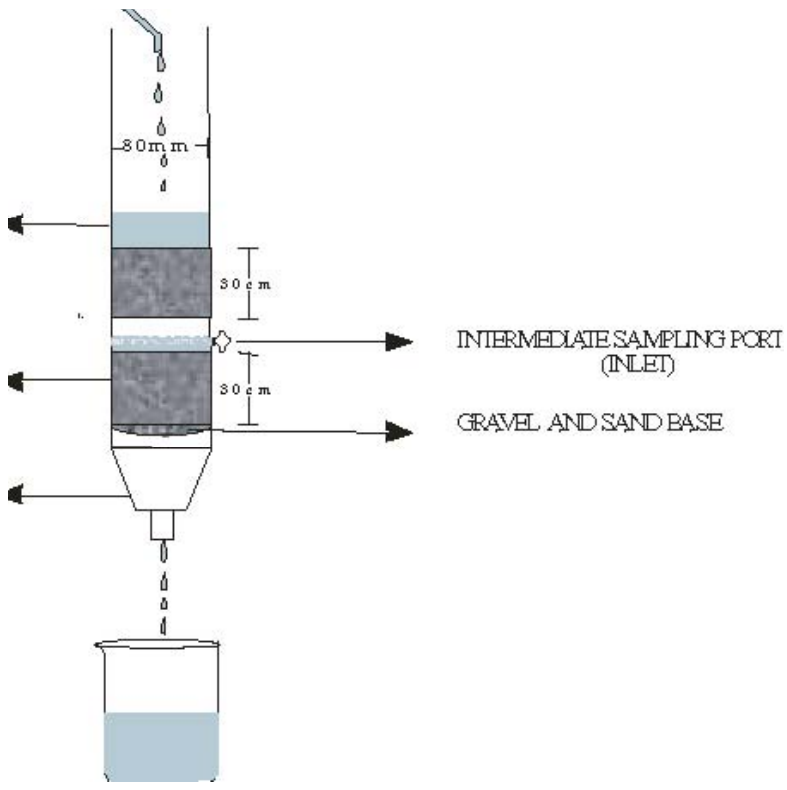

Figure 2: $\quad$ Schematic of soil column.

The columns consisted of two sections. The lower section allowed approximately $60 \mathrm{~cm}$ of soil packed. A pipe cap containing coarse gravel and sand is placed at the bottom to act as the base and screen to prevent washing out the soil. An inlet is placed at $1 / 2$ depth interval to allow reading heads (pressure) near saturated conditions.

The columns consisted of two sections. The lower section allowed approximately $60 \mathrm{~cm}$ of soil packed. A pipe cap containing coarse gravel and sand is placed at the bottom to act as the base and screen to prevent washing out the soil. An inlet is placed at $1 / 2$ depth interval to allow reading heads (pressure) near saturated conditions. For each run $200 \mathrm{ml}$ of water equivalent to $(10.5 \mathrm{~cm})$ of standing water is poured into the tube and the amount of time required for the water to completely infiltrate from each soil types is measured to determine the infiltration rate when the soil is dry, and additional $200 \mathrm{ml}$ of water is added to the tube to determine the wet infiltration rate of the soil. The infiltration rates are calculated, time required by the initial head of $10.5 \mathrm{~cm}$ to cover the distance of 
$600 \mathrm{~mm}(60 \mathrm{~cm})$ is measured and the distance covered (constant i.e., $60 \mathrm{~cm}$ ) is divided by the amount of time required for the samples to infiltrate.

\section{Geology}

Karachi region covering an area of $3225 \mathrm{~km}^{2}$ (Fig. 3) and has an arid coastal climate (Khan [9]). It is located in the northern hemisphere zone containing major desert belts. The region is surrounded by series of hill ranges in the north and Arabian sea in the south (Thomas [10]). The area under study has approximately $354 \mathrm{~km}$ with thick population density. In Karachi and its surrounding area middle and upper tertiary rock, shale-clay, sandstone and lime stone, are exposed. The lowest of these exposures are sand stone and lime stone of Nari formation of Oligocene age. Above the Nari lies the Gaj limestone and shale of Miocene to Pliocene partly Pleistocene age. The Nari formation is represented usually by soft sand stone intercalated / interlayer with limestone, shale and silts stone. The Gaj formation is represented by limestone with sub ordinate shale and sandstone. Quaternary deposits are represented by conglomerate which overlies the Mancher formation. The topography of the region is characterized by three major anticline These are separated by broad alluvial filled synclines through which Malir and Lyari rivers discharge their effluents and seasonal water into the Arabian sea (see Fig. 1).

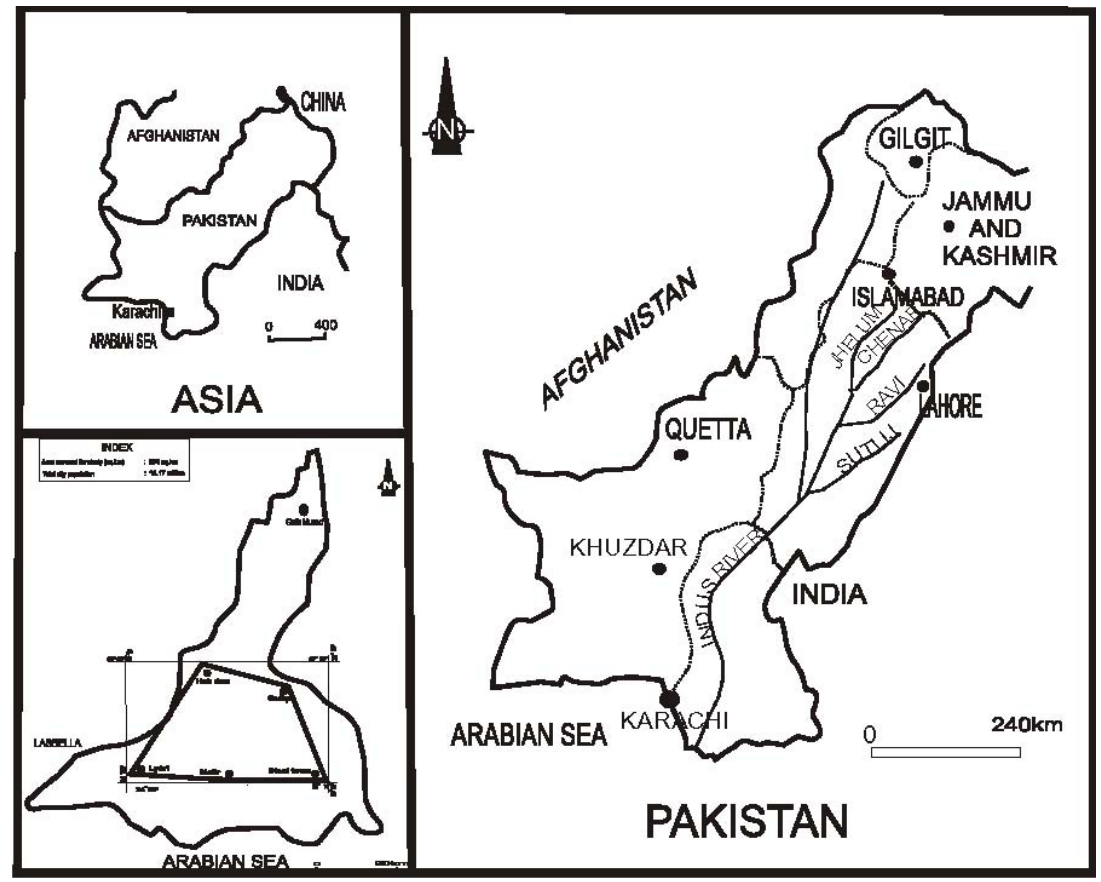

Figure 3: Location map of the study area. 


\section{Characteristics and infiltration rates of soil}

Determination of soil characteristics are most important tool to categorized the soil types and in metals removal from solution by analyzing the particle size distribution (Table 1). On the basis of percentage of individual components of silts, sands and gravel of the study area, soil has been classified into five category .

Table 1: $\quad$ Infiltration rates of soil types.

\begin{tabular}{|c|c|c|c|c|c|c|c|}
\hline \multirow{2}{*}{$\begin{array}{l}\text { SOIL } \\
\text { Types }\end{array}$} & \multicolumn{3}{|c|}{$\begin{array}{c}\% \text { By Weight } \\
\text { ( Un layered soil) }\end{array}$} & \multirow{2}{*}{$\begin{array}{c}\begin{array}{c}\text { Infiltration } \\
\text { Rate of } \\
\text { (Dry soil ) }\end{array} \\
\mathrm{mm} / \mathrm{hr} \\
\end{array}$} & \multirow{2}{*}{$\begin{array}{c}\begin{array}{c}\text { Infiltration } \\
\text { Rate of } \\
\text { (Wet soil) }\end{array} \\
\mathrm{mm} / \mathrm{hr} \\
\end{array}$} & \multicolumn{2}{|c|}{ Time *(HH:MM:SS) } \\
\hline & Gravel & Sand & Silt & & & Dry & Wet \\
\hline $\begin{array}{l}\text { Silty Sandy } \\
\text { Gravel }\end{array}$ & 45.1 & 43 & 11.9 & 85 & 30 & 07:02:00 & 20:06:00 \\
\hline $\begin{array}{c}\text { Gravely Silty } \\
\text { Sand }\end{array}$ & 10.3 & 54.1 & 35.6 & 28 & 21 & $21: 15: 12$ & $28: 57: 06$ \\
\hline Sandy Silt & - & 46.1 & 53.9 & 19 & 17 & $31: 57: 19$ & $35: 29: 10$ \\
\hline Silty Sand & - & 89.7 & 10.3 & 75 & 25 & 08:09:03 & $24: 00: 02$ \\
\hline $\begin{array}{l}\text { Silty Gravely } \\
\text { Sand }\end{array}$ & 27 & 61.9 & 10.7 & 81 & 26 & 07:04:00 & 23:00:02 \\
\hline
\end{tabular}

* $\mathrm{HH}=$ hours; $\mathrm{MM}=$ minutes; $\mathrm{SS}=$ seconds.

\section{Results and discussion}

The soil water quality data consist of aqueous concentration of trace metals $(\mathrm{Cd}$, $\mathrm{Cu}, \mathrm{Pb}, \mathrm{Zn}$ ) solution in addition to major ions ( $\mathrm{Ca}, \mathrm{Mg}, \mathrm{Na}, \mathrm{K}$ ) for this study. The samples extracted from the two intermediate sampling ports, and the bottom exist port soil extractable cations are analyzed half way through the experiment and end of experiment from five soils types sampled.

Water quality tests are conducted on stormwater that passes through the each soil type to assess the effects of the medium. Samples are collected prior to and after infiltration to compare the concentration of various constituents that have passed through the medium. Sample of the effluent draining from the tube are collected after approximately half of the each run and when all of the water is infiltrated from each medium. The percentage change is presented in Fig. $4 a-b$. In the concentration of all the trace metals and major cations the percentage of change is appear to decline after passing through the soil types by the end of the experiment (Kenneth et al. [11]). This is due to the presence of sand, silt and gravel and the absence of clay particles in the effluent which is responsible for declining effect of trace metals and cations as the leaching effect of soil in the study area has not occurred. Therefore the declining effect trace metals and cations are significant in the soil types. 
From the Fig. 4a-b, it shows that in all the soil types silty sand is comparatively better in terms of removal of pollutant from the stormwater as it does not allow contaminants to pass through it. Overall results demonstrate that dissolved concentration of $\mathrm{Cu}, \mathrm{Cd}, \mathrm{Zn}, \mathrm{Ca}, \mathrm{Mg}, \mathrm{Na}$ and $\mathrm{K}$ is approximately 64, $92,56,30,30,6$ and 38 percent respectively.

The results of the study demonstrates that the infiltration rates for all the soil types (dry samples) are faster then the corresponding wet soil; dry media range from $(19 \mathrm{~mm} / \mathrm{hrs}-85 \mathrm{~mm} / \mathrm{hrs})$ and wet media range from $(17 \mathrm{~mm} / \mathrm{hrs}-30$ $\mathrm{mm} / \mathrm{hrs}$ ). Silty sandy gravel has the highest and sandy silt has the lowest
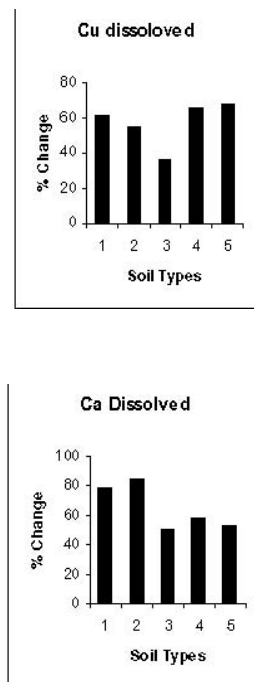
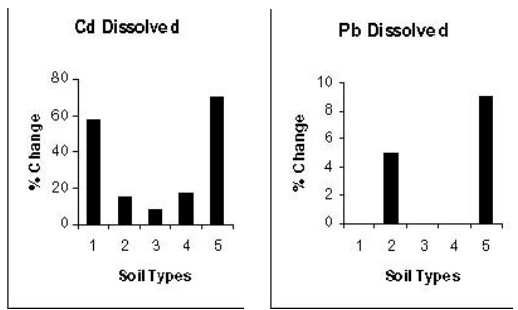

(a)

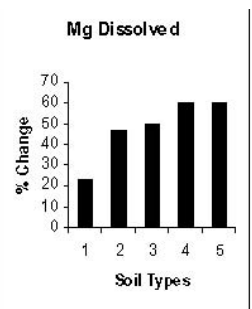

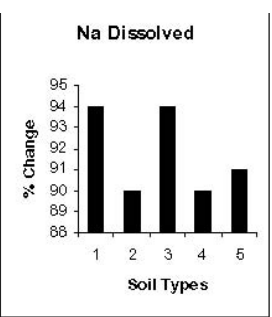

(b)
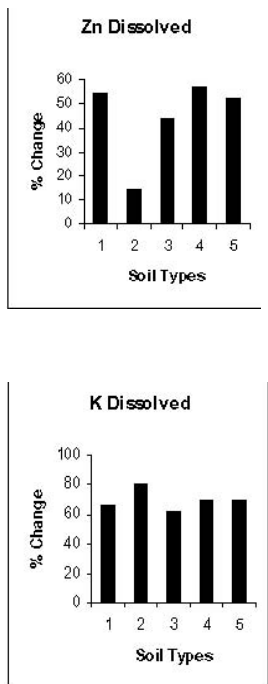

Figure 4: (a) Percentage change in trace metals (dissolved) concentration for various soil types. (b) Percentage change in major cations (dissolved) concentration for soil types. 1- silty sandy gravel. 2gravelly silty sand. 3- sandy silt. 4- silty sand. 5-silty gravelly sand.

infiltration rates among the soil types. This variation of infiltration rate of the soils is due to soil types, its composition, rainfall, and land use intensity (Ellington and Ferguson [8]).

The result of this study is in accordance with Gregory et al. [12] who studied the effect of compaction on infiltration rates on sandy soils in north central Florida and found that average non-compacted infiltration rate range from 377 to $634 \mathrm{~mm} /$ hour in dry media range as compare to average infiltration rates on compacted soils range 8 to $175 \mathrm{~mm}$ / hour in wet media range. He describes the phenomena that inadvertent soil compaction at the urban lot scale is a process that reduces infiltration rates, which lead to increase storm water, run off. This is particularly important in low impact development strategies where stormwater is intended to infiltrate rather than 
flow through a traditional stormwater network to a detention basin. Infiltration rates on compacted soils are generally much lower then the design storm water infiltration rate (Gregory et al. [12]). This implies that construction activity in the region increases the potential for runoff and the need for the large stormwater conveyance network not only due to the increase in impervious area associated with development but also because the compacted pervious area effectively approaches the infiltration behavior of an impervious surface.

As far as the soils type result is concerned in the study area, the sandy silt is seems a poor soil for infiltration because of its texture. However silty sand is comparatively better in terms of removal of pollutant from the stormwater as it does not allow contaminants to pass through it.

\section{Conclusion}

In this paper we have tried to identify the soil types suitable for trace metal attenuation and major cations of Karachi City, a coastal metropolitan city of Pakistan. The study reveals that the infiltration rates vary throughout the soil types. It further demonstrates that silty sand is comparatively better in terms of removal of pollutants from the stormwater. However infiltration rate were generally low in all the infiltrating media surveyed. The large volume of stormwater infiltrating into the basin dilutes background level of trace metal and major cations. Thus the relatively high volume of water infiltrating through stormwater basin may serve to lower the background concentration of trace metals and major cations possibly through dilution.

Experimental evidence indicates that heavy metals and major cations can be effectively retained in the soil layers. The knowledge of pollutants accumulation in or beneath infiltration systems can be used to construct infiltration systems aimed at keeping the pollution at source, where it can be controlled.

\section{References}

[1] Liu Y., Che W., and Li J., Monitor-based evaluation of pollutant load from urban storm water runoff in Beijing, Water Science \& Technology, 52(9), pp. 191-197, 2005.

[2] Ku I.F.H., Hagelin N.W., and Buxton H.T., Effects of urban storm-runoff control on ground water recharge in Nassau County, New York, Groundwater, 30(4), pp. 507-514, 1992.

[3] Appleyard S.J., Impact of stormwater infiltration on ground water quality, Perth metropolitan region, Western Australia, Environ. Geol, 21(4), pp. 227-236, 1993.

[4] Wilde F.D., Geochemistry and factors affecting ground water quality at three storm water management sites in Maryland, Maryland Geological Survey Baltimore, Rep. of Investigations, no. 59, 1994.

[5] Washington State Department of Transportation, Guidance on infiltration design rates, pp. 3, 1999. 
[6] Wang H., Ou L., Che W., and Li J., Soil infiltration and purification of storm water runoff in Beijing urban area, IWP Publishing, Water Intelligence Online, 2003.

[7] Ferguson B.K., and Deak T., Role of urban storm flow volume in local drainage problems, Journal of Water Resources Planning and Management, 120(4), pp. 523-530, 1994.

[8] Ellington M.M., and Ferguson B.K., Comparison of infiltration and detention in the Georgia Piedmont using recent hydrologic models, Proc., Georgia Water Resources Conf., Kathryn Hatcher, ed., University of Georgia, Institute of Natural Resources, Athens, Ga., pp. 213-216, 1991.

[9] Khan A.R, Geomorphology of Manhopir Spur., the Bulletin of Karachi Geomorphological Society, pp. 34-4, 1952.

[10] Thomas S.G., Arid zone geomorphology; process, form and changes in dry land, John Wiley \& Sons, New York, pp. 499-502, 1997.

[11] Kenneth C.A., Emily L.I., Lonna M.F., and William R.B., Preliminary assessment of Infiltration rate and effects on water quality of selected infiltration media for use in highway runoff retention basins in Washington States, U.S. Geological Survey, Tacoma, WA., pp. 1-17, 2001.

[12] Gregory J.H., Dukes M.D., Jones P.H., and Miller G.L., Effect of urban soil compaction on infiltration rate, Journal of Soil and Water Conservation, 61(3), 2006. 